\title{
O ENSINO MÉDIO E A INSERÇÃO JUVENIL NO MERCADO DE TRABALHO
}

\author{
MIDDLE SCHOOL AND JUVENILE INSERTION IN THE LABOR MARKET
}

LA ENSEÑANZA SECUNDARIA Y INSERCIÓN JUVENIL EN EL MERCADO DE TRABAJO

Ramon de Oliveira ${ }^{1}$

Resumo Discute-se neste artigo a relação entre a inserção da juventude no mercado de trabalho e sua passagem pelo ensino médio. Tem-se como argumento central que a recente contrarreforma do ensino médio não garantirá oportunidades universais para a conclusão da educação básica, mas, sim, promoverá a formação precarizada nas escolas públicas e reforçará a precarização do trabalho juvenil. Metodologicamente analisaram-se dados referentes à passagem da juventude pelo processo de escolarização e sua forma de inserção no mercado de trabalho. Como fontes primárias básicas foram analisados dados disponibilizados pelo Instituto Brasileiro de Geografia e Estatística, em suas Pesquisas Nacionais de Amostra Domiciliar e Censos; pesquisas realizadas pelo Ministério do Trabalho, especificamente os dados do Cadastro Geral de Empregados e Desempregados e da Relação Anual de Informações Sociais; e os dados disponibilizados pelo Instituto Nacional de Estudos e Pesquisas Educacionais Anísio Teixeira.

Palavras-chave juventude; trabalho; ensino médio.
Abstract This article discusses the relationship between the insertion of youth in the labor market and their passage through middle school. The central argument is that the recent middle education counter-reform will not guarantee universal opportunities for the completion of basic education, rather promote precarious training in public schools and reinforce the precariousness of youth labor. Methodologically, data were analyzed regarding the passage of youth through the schooling process and their insertion in the labor market. As basic primary sources, analyses were made of data provided by the Brazilian Institute of Geography and Statistics, in its National Household Sample Survey and Census; of surveys carried out by the Ministry of Labor, specifically data from the General Register of Employed and Unemployed persons and of the Annual Report of Social Information, and of data provided by the Anísio Teixeira National Institute of Educational Studies and Research.

Keywords youth; work; middle school. 


\section{Introdução}

Desde os anos 1980 encontramos nas literaturas nacional e internacional diversos trabalhos que ressaltam a importância de mudanças nos processos educativos objetivando a formação de um novo perfil de trabalhador. Essas publicações, em sua maioria, ao terem como referência o processo de reestruturação produtiva e da globalização econômica, evidenciavam que um novo perfil de trabalhador passava a ser requisitado pelo setor produtivo. As publicações destacavam também que a única forma da escola mostrar-se atual em relação à sua contribuição para este novo cenário seria reestruturar suas práticas e adotar, como norte da preparação de seus educandos, o desenvolvimento de competências como forma de aquisição de novas capacidades, asseguradoras da entrada ou permanência no mercado de trabalho (Ramos, 2001).

No Brasil, o propalado discurso da empregabilidade norteou as práticas do sistema público de ensino e, mais ainda, se instaurou como referência das ações governamentais voltadas à qualificação profissional (Oliveira, 2006).

Em âmbito empresarial afirmou-se um discurso voltado para a cobrança do poder público por uma escola básica de melhor qualidade. Segundo a perspectiva dos agentes econômicos, a má qualidade da educação básica impunha aos empresários a necessidade de desenvolver práticas formativas complementares para os alunos egressos das escolas públicas, o que aumentava seus gastos na produção de mercadorias e serviços. Estes gastos (Custo Brasil) implicavam diretamente na diminuição da competitividade dos produtos nacionais em relação aos similares estrangeiros (Oliveira, 2005).

O consenso da necessária reformulação do sistema educacional, pouco a pouco foi se fortalecendo. No entanto, tal fato não se deu pela 'unanimidade' da avaliação sobre a má qualidade dos serviços escolares. Posições distintas e até antagônicas se colocaram em relação ao que se entende por 'escola de qualidade'.

Se por um lado reconhecia-se que os altos índices de reprovação e de abandono escolar eram exemplos da má qualidade do sistema público de ensino, os baixos níveis de aprendizagem apresentados pelos egressos deste sistema evidenciavam, também, a necessidade da escola ser repensada.

Tornava-se pensamento comum que a escola não assegurava, primariamente, a aprendizagem dos conteúdos estabelecidos em sua plataforma curricular. Ao mesmo tempo, em decorrência desta não realização, ela pouco ajudava os jovens egressos a adquirirem melhor qualificação e a inserirem-se no mercado de trabalho (Cepal/Unesco, 1992).

Aos poucos, além da questão da má qualidade das escolas públicas e da sua pouca atratividade para os jovens e adolescentes, impôs-se, como um desafio aos governantes, o desemprego juvenil. Na prática, a problemática do desemprego juvenil apresentou-se como um temor social (Pochmann, 2000). 
Tornou-se comum, nos meios de comunicação de massa, notícias relativas à violência instaurada na sociedade, marcadamente vinculadas ao tráfico de drogas. Nestes noticiários, era (é) perturbadora a presença de jovens como vítimas ou protagonistas desta violência (Waiselfisz, 2014).

A incapacidade da escola de assegurar a sua promessa integradora (Gentili, 1999) como um instrumento inquestionável, garantidor de inserção no mercado de trabalho, impôs aos governantes a necessidade de proporem outras saídas para a minimização das consequências negativas deste modelo econômico centrado na descartabilidade da mão de obra. A saída encontrada foi a implementação de políticas públicas direcionadas à juventude que tinham por objetivo assegurar uma formação profissional para uma futura inserção no mercado de trabalho (Sposito e Carrano, 2003).

Diante da certeza de que a reversão do quadro de tensões vivido pela sociedade - em função do aumento da violência envolvendo os setores juvenis - não ocorreria apenas com a garantia de acesso à escola, inúmeras ações governamentais foram estabelecidas com o objetivo de reverter - via ação dos governos estaduais, municipais e principalmente do governo federal - a falta de perspectiva de futuro para a juventude brasileira. Neste sentido, nas últimas duas décadas foram implementados programas voltados para a qualificação profissional da juventude. Dentre os quais se destacam, no governo FHC, o Plano Nacional de Qualificação do Trabalhador (Planfor); ${ }^{2}$ no governo Lula, o Programa Nacional de Qualificação (PNQ) e, no governo Dilma, o Programa Nacional de Acesso ao Ensino Técnico e Emprego (Pronatec). ${ }^{3}$

Mais recentemente, durante os governos do presidente Luis Inácio da Silva e da presidenta Dilma Roussef, listamos alguns programas que colocaram a questão da qualificação profissional como um dos seus eixos centrais: Programa Nacional de Inclusão de Jovens (Projovem), Programa Nacional de Estímulo ao Primeiro Emprego (PNPE), Programa de Integração de Educação Profissional ao Ensino Médio na Modalidade de Educação de Jovens e Adultos (Proeja), Programa Escola de Fábrica e, mais recentemente, o Pronatec.

Passados os anos, persiste, na interpretação governamental e das elites empresariais, a compreensão segundo a qual a saída para a minimização da insatisfação e da insegurança juvenil está na ampliação de ações públicas de qualificação profissional. Ou, como foi (re)afirmado recentemente na contrarreforma do ensino médio, na 'garantia', aos jovens mais pobres, de uma profissionalização ainda no âmbito da educação básica.

Considerando este contexto e analisando o quadro atual de aprofundamento do desemprego juvenil, entendemos ser pertinente discutir (qual) a contribuição da escola para o ingresso dos jovens brasileiros no mercado de trabalho.

Pressupomos a existência de uma crise na relação entre as juventudes e a escola. As juventudes colocam em suspeição a influência da escola em suas vidas futuras, pois esta instituição tem sido pouco significativa para elas, no 
momento presente (Sposito, 1993). As escolas públicas de ensino médio, em geral, desconsideram que seus educandos têm histórias próprias para além dos muros escolares. E embora seja inquestionável o aumento do nível de escolarização dos jovens trabalhadores brasileiros, este não foi suficiente para assegurar-lhes a obtenção de um emprego (Pochmann, 2001, 2008).

Houve um aumento das taxas de conclusão do ensino médio e um aumento do número de pessoas, entre 17 e 19 anos, com toda a educação básica concluida. Mas, apesar disso, ainda persiste na realidade brasileira um altíssimo número de jovens fora das escolas, especificamente a de ensino médio, bem como é extremamente elevado o quantitativo de indivíduos que, mesmo ingressando no ensino médio, não consegue concluí-lo.

Com esse contexto como referência, sustentaremos que a recente contrarreforma do ensino médio não promoverá oportunidades universais para a conclusão da educação básica. Além disto, demonstraremos que ela, no âmbito da qualificação profissional, promoverá a formação precarizada de um maior contingente de trabalhadores. Seja pelo reforço da distribuição desigual do conhecimento escolar em função da imposição dos itinerários formativos, seja pelo empobrecimento da formação profissional ofertada, o sistema público de ensino reforçará os mecanismos que impõem a um grande contingente de jovens, quando muito, a obtenção de postos de trabalho precarizados.

A flexibilização das escolhas, tão enaltecida pelos defensores da contrarreforma e alardeada pelos veículos de comunicação, caracteriza-se como mais um dos mecanismos para fazer da escola espaço de legitimação das desigualdades sociais. Em outras palavras, a reforma expressa uma ação concreta de manter os atuais níveis de desigualdade de acesso à escola de ensino médio, mas também serve como dispositivo para assegurar ao capital a ampliação da disponilidade de trabalhadores sujeitos à precarização.

Entendemos, como já nos alertava Frigotto (1989), que a baixa qualidade da escola pública, especificamente a de ensino médio, tem sido funcional ao processo de acumulação capitalista. Ao promover a formação de um contingente de trabalhadores de forma aligeirada, assegura apenas o domínio da qualificação básica e necessária à realização de tarefas com baixo teor científico. A escola pública, ao distribuir desigualmente o conhecimento acumulado, seja pela má qualidade da formação desenvolvida, seja por seus mecanismos de exclusão, tem sido útil à acumulação de capital e tem favorecido, cada vez mais, a inserção dos jovens em postos de trabalho precarizados. Assim, contrariamente aos reclamos do empresariado, a educação básica de baixa qualidade não tem sido um empecilho, mas, sim, um item constituinte e fortalecedor deste modelo de acumulação (Oliveira, 2015).

Para a elaboração destas análises, recorremos aos dados disponibilizados pelo Instituto Brasileiro de Geografia e Estatística (IBGE) - nas Pesquisas 
Nacionais de Amostra Domiciliar (PNADs) e Censos -, os quais são fundamentais para discutirmos os movimentos recentes do mercado de trabalho e a influência da educação básica no ingresso e na forma de participação da juventude no mercado laboral.

Para ampliar e aprofundar nossa compreensão a respeito da realidade vivenciada pelas juventudes trabalhadoras, direcionamo-nos às pesquisas realizadas pelo Ministério do Trabalho, especificamente aos dados do Caged ${ }^{4}$ (Cadastro Geral de Empregados e Desempregados) e da RAIS 5 (Relação Anual de Informações Sociais). E para a análise da interferência do fator 'escola' neste processo, apoiamo-nos em dados disponibilizados pelo Inep (Instituto Nacional de Estudos e Pesquisas Educacionais Anísio Teixeira).

\section{A escolarização da juventude brasileira e a contrarreforma do ensino médio}

No Brasil, a juventude é considerada o grupo com idade entre 15 e 29 anos, o qual, segundo os dados do IBGE, no ano de 2014, representava 24,1\% da população, quase 49 milhões de pessoas. Delimitaremos nossas análises à situação daqueles com idade entre 15 e 24 anos, em virtude de as nossas argumentações estarem direcionadas aos que deveriam estar cursando o ensino médio (entre 15 e 17 anos), bem como aos que deveriam estar matriculados na educação superior, cuja idade 'ideal' situa-se entre 18 e 24 anos. Falamos de um grupo de aproximadamente 34 milhões de pessoas.

Deste grupo de 15 a 24 anos de idade, cerca de 14,2 milhões (42\%) fazem parte da população economicamente ativa (IBGE, 2014), ou seja, trabalham ou estão em situação de desemprego. Para este grupo, seu nível de escolarização, bem como a qualidade da formação adquirida nos bancos escolares, torna-se fator influente sobre o tipo de postos de trabalho ocupados ou sobre sua situação de desemprego.

Acreditamos ser importante trazer informações relativas ao perfil econômico da juventude brasileira, pois será constatado que a condição econômica não só é um dos determinantes do processo de escolarização, mas define, talvez de forma mais contundente, a forma de inserção no mercado de trabalho. Vejamos a Tabela 1 .

\section{Tabela 1}

\begin{tabular}{|c|c|c|c|c|c|c|}
\hline Idade & Total (x 1.000) & Até $1 / 2$ (SM) & $1 / 2$ a 1 (SM) & 1 a 2 (SM) & 2 a 3 (SM) & Mais de 3 (SM) \\
\hline $15-17$ & 10.324 & $40,9 \%$ & $28,8 \%$ & $17,2 \%$ & $4,4 \%$ & $5 \%$ \\
\hline 18-19 & 6.591 & $33,3 \%$ & $28,7 \%$ & $24,9 \%$ & $5,8 \%$ & $6,0 \%$ \\
\hline $20-24$ & 17.076 & $28,2 \%$ & $27,6 \%$ & $24,5 \%$ & $7,2 \%$ & $8,0 \%$ \\
\hline
\end{tabular}

Fonte: Censo demográfico 2010 (IBGE, 2011). 
De acordo com a Tabela 1, persiste na sociedade brasileira uma concentração do contingente populacional nos estratos de renda muito baixos. Quase $70 \%$ dos jovens entre 15 e 17 anos participam de famílias com renda per capita inferior a um salário mínimo. Mais desolador é o fato de que pelo menos $40 \%$ desta população juvenil participam de famílias cujas rendas per capita mensais não chegam, sequer, à metade de um salário mínimo.

Ao considerarmos a Tabela 1, observamos haver, com o aumento da faixa etária, um aumento de renda, e tal fato pode ser explicado pela inserção destes jovens no mercado de trabalho. De acordo com os dados do IBGE referentes ao ano de 2015 (IBGE, 2016), o percentual de jovens entre 18 e 24 que já trabalhavam era quase três vezes superior aos que estavam na faixa etária entre 15 e 17 anos. Ou seja, cerca de 55,1\% dos jovens entre 18 e 24 anos estavam trabalhando enquanto, no outro grupo, este percentual era de 19,1\%.

A maior presença dos jovens entre 18 e 24 anos no mercado de trabalho e a consequente melhoria das suas condições de renda indicam que, por um lado, a obtenção de um emprego implica direta e imediatamente na condição de vida juvenil e das suas famílias. Por outro lado, ao sabermos que mais de $76 \%$ destes jovens abandonaram a escolarização e, por algum motivo, não conjugaram o trabalho com a continuidade dos estudos (IBGE, 2016), preocupa-nos o quanto esta entrada no mercado de trabalho - se impõe como um - forte limite à melhoria na sua condição funcional e salarial no futuro.

A inserção no mercado de trabalho tem uma implicação direta na continuidade do processo de escolarização e de qualificação profissional juvenil. Como para a maioria dos jovens mais pobres, a passagem pela educação básica é praticamente o único momento de adquirir os conhecimentos minimamente demandados pelo mercado de trabalho, qualquer movimento de restrição do acesso ao conhecimento escolar amplia a desigualdade social. Nesse sentido, a contrarreforma do ensino médio mostra-se, ao contrário do propagandeado pelo governo federal, como acentuadora do acesso a empregos precarizados. Precarização que se intensifica com as medidas tomadas pelo governo Temer, de cunho neoliberal, voltadas à flexilibização dos direitos trabalhistas.

Ao afirmar que "atualmente o ensino médio possui um currículo extenso, superficial e fragmentado, que não dialoga com a juventude, com o setor produtivo, tampouco com as demandas do século XXI" (Brasil, 2016), o governo Temer, de forma autoritária e sem garantir o debate amplo e includente, valoriza apenas o proposto por aqueles favoráveis à contrarreforma nos momentos de sua discussão no Congresso Nacional (Ferretti e Silva, 2017). Ao fazer a opção por aligeirar mais ainda a formação do ensino médio, estabeleceu uma Base Nacional Comum Curricular (BNCC) que não ultrapassa 1.800 horas (dentre as três mil horas previstas para todo o ensino médio), dificultando o acesso a conteúdos necessários à formação cidadã. 
Ao retirar do currículo as disciplinas de Artes, Filosofia, Sociologia e Espanhol e considerar como obrigatórias em todas as séries do ensino médio apenas Português e Matemática, e também a Língua Inglesa, mas sem precisar a sua participação na BNCC, o governo fez a opção por um modelo de formação cuja perspectiva é um trabalhador sem autonomia e criticidade. Esta sonegação de acesso a conteúdos aponta para a precarização da formação escolar e contribuirá para o empobrecimento da formação de trabalhadores, direcionando-os a postos de trabalho precarizados.

$\mathrm{O}$ aprofundamento da crise econômica vivenciada nos últimos três anos, ampliou o quantitativo de jovens, entre 18 e 24 anos, desempregados. Este fato relaciona-se diretamente com o número de jovens que não estudam nem trabalham. Segundo o IBGE, no ano de 2015, o percentual de jovens nesta faixa etária, fora da escolarização e também fora do mercado de trabalho, atingiu o montante de $27,4 \%$.

Embora seja inquestionável o crescimento substantivo do número de matrículas no ensino médio (saindo de um pouco mais de 4 milhões em 1992, para mais de 8 milhões em 2015 (INEP, 2016)), as ações sociais que têm por objetivo assegurar um maior contingente de jovens na escola, não ampliaram a igualdade de acesso entre os distintos estratos sociais.

Quando da realização do censo demográfico pelo IBGE, em 2010 (IBGE, 2012), apontava-se que o pertencimento a um estrato econômico tem interferência real nas possibilidades de frequência à escola. Naquele momento, mostrava-se que a presença de jovens com idade entre 18 e 19 anos, vinculados a famílias com renda per capita de até 1 salário mínimo, não ultrapassava o índice de 40,3\%. Este índice, para os grupos com renda per capita entre 2 e 3 salários mínimos, chegava a 56,1\%. Passados alguns anos, esta realidade tem permanecido. De acordo com os dados apresentados no Anuário Brasileiro da Educação Básica de 2017 (Todos pela Educação, 2017), a taxa de atendimento no ensino médio para o quartil mais rico da população chega a $86,6 \%$, reduzindo-se este índice para apenas $52,5 \%$, quando nos direcionamos para o quartil mais pobre, conforme a explicação do analista:

Chama atenção a discrepância entre as redes de ensino, pois, em 2015, a proporção de estudantes na faixa etária de 15 a 17 anos de idade que frequentavam rede pública com distorção idade-série era 3,6 vezes maior do que na rede particular. Além disso, os $20 \%$ com os menores rendimentos da distribuição do rendimento mensal domiciliar per capita ( $1^{\circ}$ quinto) possuíam taxa distorção idade-série 5,0 vezes maior do que a taxa dos estudantes pertencentes aos $20 \%$ com os maiores rendimentos ( $5^{\circ}$ quinto), fazendo com que o atraso escolar afetasse $40,7 \%$ desses estudantes em 2015. Em 2005, a distância entre o $1^{\circ}$ quinto e o $5^{\circ}$ quinto era ainda maior (6,2 vezes) (IBGE, 2016, p. 60). 
À medida que aumenta a idade do jovem, a sua permanência na escola tende a diminuir significativamente se ele pertencer aos estratos econômicos mais baixos. A possibilidade de conclusão do ensino médio por jovens com idade posterior aos 17/18 anos vai diminuindo, pois, a partir desta idade, eles, muitas vezes obrigados, abandonam a escolarização.

De acordo com os dados do IBGE (2014), 44,2\% dos quase 6,9 milhões de jovens entre 18 e 19 anos, um pouco mais de 3 milhões continuavam estudando, dentre estes, cerca de 965 mil frequentavam o ensino superior. Entre a população juvenil que cursava a educação básica ou que já havia abandonado a escolarização, era substantivo o percentual de jovens empregados ou a procura de um emprego, sem terem obtido a certificação de ensino médio (IBGE, 2016). Esta condição, no nosso entender, tem implicação na forma como ocorreu o ingresso no mercado de trabalho e na forma como se dá sua permanência.

Preocupante é o fato de mais de 55\% dos jovens nesta faixa etária terem abandonado a escolarização. Muitos não chegaram a concluir toda a educação básica e, alguns, nem sequer o ensino fundamental, como pode ser constatado na análise do IBGE:

$\mathrm{O}$ efeito do atraso escolar também pode ser observado entre os jovens de 15 a 17 anos de idade que estavam fora da escola. No Brasil, em 2015, 15,0\% dos jovens dessa faixa etária não estudavam, totalizando cerca de 1,6 milhão de jovens. Entre os jovens que haviam evadido a escola precocemente sem terminar o ensino médio (1,3 milhão de jovens), 61,4\% abandonaram a escola sem concluir o ensino fundamental, 22,1\% concluíram o ensino fundamental e $16,4 \%$ tinham ensino médio incompleto. Isso significa que a maioria desses jovens sequer estava apta a ingressar no ensino médio $(61,4 \%)$, evidenciando que parte significativa da evasão escolar dessa faixa etária ocorre em etapas que antecedem esse nível (IBGE, 2016, p. 61).

Ao retomarmos as críticas à contrarreforma do ensino médio, observamos que culpabilizar este nível de ensino sem considerar o escândalo da evasão escolar por parte dos jovens ainda no ensino fundamental é mais uma de suas incongruências.

Apesar de tantas mudanças ocorridas ao longo dos anos, o ensino médio apresenta resultados que demandam medidas para reverter esta realidade, pois um elevado número de jovens encontra-se fora da escola e aqueles que fazem parte dos sistemas de ensino não possuem bom desempenho educacional (Brasil, 2016).

O governo, ao justificar a necessidade da reforma, omite um problema estrutural na educação brasileira. Nem o ensino médio garante para os jovens 
o acesso, a permanência e a aprendizagem efetiva dos componentes curriculares, nem o ensino fundamental. A questão que se coloca é: qual o motivo gerador deste silenciamento? E porque esta opção pelo ensino médio implicou no projeto estabelecido?

Embora em momentos diferentes de nossa história, as elites nacionais desencadearam reformas que visavam a reafirmação da dualidade no processo educativo. No entanto, neste momento específico, a contrarreforma do ensino médio busca não apenas reafirmação da dualidade. Expressa-se também como reação a todos os avanços dos últimos anos, daí a importância de se evidenciar o seu caráter regressivo (Motta e Frigotto, 2017).

Ainda que critiquemos os limites dos governos Lula e Dilma na efetivação de um projeto de ensino médio politicamente comprometido com os interesses da juventude trabalhadora, nestes governos experimentamos alguns avanços na construção de um projeto político emancipatório. Referimo-nos à experimentação de inovações pedagógicas pautadas na integração entre a educação profissional e a educação geral (Ensino Médio Integrado) e ao Programa Ensino Médio Inovador (Proemi). Este último permitiu a muitas escolas das redes estaduais experenciarem inovações que promoveram enriquecimento nas suas práticas formativas. A reforma apresenta-se neste contexto como mecanismo de erradicação de experiências que visavam amadurecer novas dinâmicas nas escolas das juventudes trabalhadoras.

Esta reforma está pautada pela fragmentação, pelo empobrecimento curricular e pela afirmação da dualidade, por representar um projeto de formação humana que visa a restabelecer, no plano educativo, o histórico apartheid social, político e econômico presente no modelo republicano brasileiro. Neste sentido, como nos alertou Kuenzer (2007), devemos encarar em nossas análises o fato de que os avanços conquistados no âmbito do ensino médio têm como limite a própria dualidade persistente na sociedade brasileira. É na própria dualidade da sociedade de classes que reside e se origina o projeto de reforma que impôs os retrocessos hoje presenciados.

Em consequência, a superação da dualidade não é uma questão a ser resolvida através da educação, mediante novas formas de articulação entre o geral e o específico, entre teoria e prática, entre disciplinaridade e transdisciplinaridade; ou mediante uma nova concepção de competência que tenha impacto nas políticas e programas de formação de professores. A dualidade só será superada se superada for a contradição entre a propriedade dos meios de produção e da força de trabalho (Kuenzer, 2007, p. 1.162).

Embora a taxa de escolarização bruta ${ }^{6}$ para os jovens entre 15 e 17 anos seja superior a $85 \%,{ }^{7}$ isto não quer dizer que estes jovens estejam frequentando o ensino médio. Os dados demonstram que este não é apenas um problema de distorção idade/série. Trata-se de algo muito mais dramático, relacionado 
ao retardamento da chegada a esta fase da escolarização e à não permanência destes jovens na escola. Consequentemente, em virtude do alto índice de abandono escolar, são poucos os que, mesmo com atraso, ao chegarem aos 18 ou 19 anos concluem o ensino médio.

No censo da educação básica relativo ao ano de 2015 (disponibilizado no site do Inep), aponta-se que tivemos cerca de 6,8 milhões de matrículas no ensino médio nas escolas das redes estaduais. Neste mesmo ano, a taxa de abandono nesse nível de ensino foi da ordem de 8,7\%. Ou seja, cerca de $590 \mathrm{mil}$ jovens abandonam o ensino médio. Infelizmente não podemos identificar, com precisão, o quantitativo de jovens que retomam os estudos nos anos seguintes.

Quando da realização do censo de 2010, o IBGE constatou que do total da população entre 18 e 19 anos, pelo menos 42,5\% não tinham sequer o ensino médio incompleto (IBGE, 2011). Uma nova pesquisa realizada em 2014 (IBGE, 2015) confirmou poucas alterações nesta realidade, pois, ao se levantar o número de pessoas entre 20 e 22 anos portadoras da certificação do ensino médio, observou-se ser este percentual de apenas 60,8\%. Em outras palavras, cerca de $40 \%$ dos jovens brasileiros chegaram à idade de 20 anos sem terem concluído toda a educação básica, evidenciando mais uma vez o fato de que a chegada à maioridade é, para a grande maioria da juventude trabalhadora e pobre, o prazo limite para a conclusão da educação básica.

No nosso entendimento esta informação é grave, pois os jovens nesta idade são, por diversos fatores, cada vez mais influenciados ou obrigados a ingressar, quando já não ingressaram, no mercado de trabalho. Começar a trabalhar, embora não seja a única e, talvez, nem a principal causa do abandono da escola, por diversos motivos, tem determinado a impossibilidade quase definitiva da conclusão da educação básica.

$\mathrm{O}$ abandono parece não encontrar, nas ações dos governos estaduais ou do governo federal, nenhum tipo de solução. De acordo com os dados apresentados pelo IBGE (2015), desde 2011, mais de $98 \%$ das crianças de 6 a 14 anos frequentam a escola. No entanto, para os jovens entre 15 e 17 anos, os índices registrados são muito distintos destes e chegam a apenas $85,4 \%$.

Preocupante também é o não crescimento contínuo destes índices, o que configura a ausência de uma política real de universalização do ensino médio e de uma política asseguradora da permanência dos jovens na escola, como pode ser demonstrado na Tabela 2.

\section{Tabela 2}

\begin{tabular}{|c|c|c|c|c|c|c|c|c|c|}
\hline \multicolumn{10}{|c|}{ Taxa de frequência bruta a estabelecimento de ensino da população entre 15 e 17 anos (\%) } \\
\hline 2004 & 2005 & 2006 & 2007 & 2008 & 2009 & 2011 & 2012 & 2013 & 2014 \\
\hline 81,8 & 81,6 & 82,1 & 82,1 & 84,1 & 85,2 & 83,7 & 84,2 & 84,3 & 84,3 \\
\hline
\end{tabular}


Se os dados referentes à frequência bruta não são animadores, o mesmo ocorre em relação à frequência líquida. ${ }^{8} \mathrm{~A}$ discrepância de dados em relação à frequência líquida no ensino fundamental e no ensino médio demonstram como o abandono escolar é uma realidade aterradora. Contudo, a maneira pela qual o governo brasileiro tratou desta situação, através da reforma, não nos permite acreditar que ela modificará positivamente algo nesta realidade.

A saída governamental, que cria os itinerários formativos como forma de tornar o ensino médio 'mais atrativo' e 'mais flexível' para os estudantes, assenta-se no falso pressuposto segundo o qual, está na 'pesada' estrutura curricular a explicação dos índices desconfortáveis apresentados nesta última etapa da educação básica, conforme a análise seguir:

Isso é reflexo de um modelo prejudicial que não favorece a aprendizagem e induz os estudantes a não desenvolverem suas habilidades e competências, pois são forçados a cursar, no mínimo, treze disciplinas obrigatórias que não são alinhadas ao mundo do trabalho, situação esta que, aliada a diversas outras medidas, esta proposta visa corrigir, sendo notória, portanto, a relevância da alteração legislativa (Brasil, 2016).

Aliada a esta lógica da flexibilização, cria-se a ilusão de que com a 'profissionalização' durante o ensino médio, os estudantes passam a encontrar possibilidades reais de concretizarem seus projetos de vida.

(...) a presente medida provisória propõe como principal determinação a flexibilização do ensino médio, por meio da oferta de diferentes itinerários formativos, inclusive a oportunidade de o jovem optar por uma formação técnica profissional dentro da carga horária do ensino regular (Brasil, 2016).

As saídas encontradas pelo governo distanciam-se muito dos fatores geradores do abandono e da má qualidade da formação adquirida durante o ensino médio. O governo silencia o fato de que, em diversas pesquisas nas quais os estudantes têm a oportunidade de apontarem suas insatisfações em relação à escola, eles explicitam não serem apenas as 'disciplinas' os aspectos negativos da escolarização. Na própria pesquisa citada pelo governo federal, na exposição de motivos alegados para justificar a necessidade da reforma do ensino médio, os estudantes mostraram insatisfações com as posturas dos professores em sala de aula, o não uso de recursos tecnológicos, a má qualidade da infraestrutura, a falta de segurança, a má conservação das escolas etc. Além disso, 42\% declararam não terem tido pelo menos uma das aulas programadas para o dia anterior à realização da pesquisa (Torres et al., 2013). 
Em pesquisa concluída no ano de 2013 com jovens do ensino médio que tinham entre 15 e 17 anos, em várias capitais brasileiras, Dayrell e Jesus (2013), analisaram a exclusão dos jovens do processo de escolarização. Os autores nos chamaram atenção para uma miríade de motivos que levavam os jovens a abandonar a escola. Coerentemente com o que foi destacado anteriormente, e em confronto com a lógica governamental, os pesquisadores evidenciaram as variadas questões a serem consideradas para se justificar ou entender os determinantes da evasão escolar juvenil. A estrutura curricular, certamente não foi o único elemento a ser considerado:

Ao se referirem às suas trajetórias escolares, e às suas expectativas educacionais e ocupacionais, os jovens depoentes não reduzem sua descrição aos espaços escolares. Ao mesmo tempo em que explicam suas trajetórias fazendo conexões com aquilo que vivenciam para além dos muros escolares, denunciam as relações tensas e contraditórias que se estabelecem entre estes dois mundos. Os problemas de infraestrutura dos prédios escolares, os currículos escolares que pouco ou nada dialogam com as experiências de vida e com os projetos de futuro dos jovens, os professores despreparados ou desmotivados para lidar com estes jovens estudantes, a violência observada no interior de algumas escolas podem ser citados como alguns dos problemas que, certamente, desempenham papel importante neste contexto de exclusão escolar. Todavia, as barreiras e gargalos identificados pelos jovens entrevistados no que tange a continuidade de escolarização não podem ser reduzidas à aspectos estritamente escolares (Dayrell e Jesus, 2013, p. 91).

Embora reconheçamos um maior nível de preocupação dos governos Lula e Dilma com a ampliação do acesso e da conclusão do ensino médio, as políticas por eles implementadas não foram capazes de impedir que o processo de escolarização continue contribuindo para a manutenção das formas desiguais de incorporação da juventude brasileira ao mercado de trabalho. Também não podemos deixar de lembrar que ainda no governo Dilma evidenciava-se o interesse em promover uma reforma do ensino médio. Nesse sentido, vale a pena mencionar que tramitava na Câmara dos Deputados o projeto de lei (PL n. 6.840/2013) do deputado federal Reginaldo Lopes (PT-MG), que entre algumas semelhanças com a atual contrarreforma, propunha que na última série do ensino médio fosse estabelecida a existência de opções formativas, entre as quais a formação profissional.

A problemática do ensino médio não é uma questão apenas de ordem curricular, como vem sendo apregoado pelo governo federal e pela mídia, ao buscarem um consenso em torno desta reforma. A questão central merecedora de enfrentamento diz respeito à desigualdade social que ainda impera e se acentua em virtude das reformas instauradas pelo governo Temer, dentre as quais encontra-se a autoritária contrarreforma do ensino médio. 
Na relação entre acesso desigual à escolarização e arranjar um emprego é bom lembrar que, embora as condições econômicas e uma certa cultura determinem a entrada dos jovens no mercado de trabalho, essa aproximação ocorre precocemente e, na maioria das vezes, em condições precárias. Na prática, este ingresso prematuro e precarização são alimentados pela realidade de privações vivenciada por muitas famílias, de forma que a própria possibilidade de muitos jovens viverem a condição juvenil é determinada por sua entrada, prévia, no mercado de trabalho (Dayrell, 2007). Esta entrada imatura explica um pouco o motivo pelo qual os jovens são os mais afetados pelo problema do desemprego. De qualquer forma, apesar das diversas explicações a respeito do desemprego juvenil, concordamos com Castro e Aquino (2008), ao afirmarem ser ele uma problemática social.

Articulando a passagem pela escola e o ingresso no mercado de trabalho, observa-se um incremento do nível de escolaridade da população economicamente ativa, principalmente a juvenil. No entanto, em virtude dos índices bastante negativos em relação à conclusão do ensino médio, muitos jovens inserem-se no mercado de trabalho sem terem ainda concluído a educação básica. De acordo com os dados registrados pelo Departamento Intersindical de Estatística e Estudos Socioeconômicos (DIEESE, 2015), com base em dados fornecidos pelo IBGE, referentes à PNAD de 2014,64,6\% dos jovens entre 18 e 24 anos acessaram seu primeiro emprego, em 2014, sem terem concluído o ensino médio.

Chamamos constantemente atenção para a entrada dos jovens no mercado de trabalho sem a conclusão da educação básica, tanto por considerarmos esta conclusão uma referência mínima para o exercício pleno da cidadania como também pelo fato de vivenciarmos uma maior intensificação das práticas patronais de ampliação dos níveis de exigência para contratação de trabalhadores. No nosso entender, a não conclusão do ensino médio tenderá a se estabelecer como um mecanismo quase que intransponível para a entrada no mercado formal de trabalho, não precarizado.

A reforma do ensino médio não enfrenta os baixos níveis de conclusão da última etapa da educação básica. Muito menos se coloca como mecanismo capaz de elevar a qualidade do ensino médio. Seria ela fortalecedora da precarização? Sim.

Sabemos que, a despeito das fragilidades das políticas educacionais para ampliação dos contingentes de jovens com o ensino médio concluído, foi ampliado o quantitativo de pessoas empregadas ou à procura de emprego possuidoras da educação básica completa. No entanto, em virtude do aumento do desemprego, os empregadores aproveitam-se desta realidade e estabelecem mecanismos mais rígidos de contratação, dentre os quais se destaca a exigência por maior nível de escolarização. Logo, a certificação de ensino médio configura-se, muitas vezes, como patamar mínimo de exigência na hora de contratação, ainda que seja para um emprego precário. 
Para se ter uma ideia melhor do nível de seletividade estabelecido no mercado de trabalho (formal e informal) brasileiro, ao se considerar a escolarização, o IBGE (2015) registra que, entre os anos de 2004 e 2014, a população ocupada cresceu de 82,7 milhões para 98,1 milhões, com um incremento de $18,6 \%$. Neste mesmo intervalo de tempo a população ocupada detentora do ensino médio completo ou maior escolarização cresceu de 28,7 milhões para cerca de 49,3 milhões, o que representa um aumento da ordem de 71,8\%. Ou seja, o percentual de crescimento de pessoas ocupadas e detentoras do ensino médio foi quase quatro vezes maior que o índice de crescimento do quantitativo das pessoas ocupadas.

De acordo com a RAIS de 2013, no que correspondia apenas aos empregos formais, $67,5 \%$ dos trabalhadores empregados haviam, pelo menos, concluído o ensino médio, independentemente de estarem no ensino superior ou de o terem concluido. Logo, no mercado formal, é bem maior a presença de trabalhadores com o ensino médio completo. No conjunto geral de trabalhadores ocupados, seja na informalidade ou com carteira assinada, a presença de portadores de certificação de ensino médio é de apenas $50 \%$, mas, no mercado formal, este percentual chega a $67,5 \%$.

Quando analisamos a PNAD de 2013, constatamos que, naquele ano, a população ocupada era da ordem de 95,3 milhões de pessoas, das quais, cerca de 40 milhões estavam na informalidade. Destes 40 milhões, 10,4 milhões (apenas 25,9\%) tinham uma escolaridade igual ou superior ao ensino médio. Ou seja, no mercado informal, mais de $74 \%$ dos trabalhadores não concluíram toda a educação básica. Estes dados evidenciam o quanto ter a certificação é um dos diferenciais em relação à forma de inserção no mercado de trabalho.

Ao considerar estas informações, retornamos à questão sobre o quanto a reforma reforçará as formas precarizadas de trabalho. Embora não haja relação de causa-efeito imediato entre a reforma do ensino médio e a dinâmica do mercado de trabalho, queremos destacar o fato da concluir o ensino médio não ter se configurado como garantia de emprego, muito menos como determinante da forma de o trabalhador se inserir no mercado de trabalho. Os dados anteriormente apontados indicam que não possuir o certificado do ensino médio favorece a entrada no mercado informal e, por conseguinte, formas precarizadas de trabalho. Logo, é impertinente o discurso governamental, segundo o qual a formação profissional no âmbito do ensino médio tem poder para confrontar-se com os mecanismos de seletividade postos pelo mercado de trabalho.

Kuenzer (2017), que também se posicionou contrariamente à contrarreforma, já em texto anterior (Kuenzer, 2007) alertava para o fato de que não está na figura do trabalhador a explicação para seu ingresso no mercado de trabalho, mas, sim, na dinâmica do processo de acumulação do capital. É o movimento do capital o determinante de suas necessidades de mão de obra. 
Logo, mobilizar o sistema educacional para forjar trabalhadores aptos às necessidades do mercado é desconhecer que a dinâmica da acumulação capitalista não tem nenhuma linearidade no que se refere à forma de contratação de trabalhadores e às formas de extração de mais-valia. Ser trabalhador flexível não se estrutura pela multiplicidade de conhecimentos ou pelo grau de escolarização e de domínio do saber científico. O trabalhador flexível é aquele que se apresenta capaz de exercer as atividades demandadas pelo processo de produção de serviços/mercadorias, independentemente de um maior nível de exigência intelectual ou formativo.

Ser flexível, para estes trabalhadores, significa adaptar-se ao movimento de um mercado que inclui/exclui, segundo as necessidades do regime de acumulação. A competência, nos pontos desqualificados das cadeias produtivas, resume-se ao conhecimento tácito, demandado pelo trabalho concreto. Não há, para estes trabalhadores que atuam nos setores precarizados, demandas relativas ao desenvolvimento da competência de trabalhar intelectualmente em atividades de natureza científico-tecnológica, em virtude do que não se justifica formação avançada (Kuenzer, 2007, p. 1.169).

\section{Considerações finais}

O mercado informal ou o trabalho precarizado tem sido o destino de parte considerável daqueles que não completaram o ensino médio ou, mesmo tendo concluído, não dispõem de uma formação asseguradora de um trabalho menos precarizado.

Os dados relativos ao desemprego juvenil nos permitem constatar que, embora exista maior nível de escolarização dos trabalhadores ocupados, ainda persistem fatores impeditivos da presença mais consistente dos jovens na ocupação dos postos de trabalho disponíveis.

Contraditoriamente ao aumento do nível de escolarização, são os jovens os que mais sofrem com o desemprego, as condições de trabalho precarizadas e a menor retribuição salarial. Neste sentido, a conclusão do ensino médio é um dispositivo importante para a conquista de um emprego não precarizado. No entanto, as elites brasileiras, em sua articulação com o grande capital mundial na exploração dos trabalhadores, empregam todos os mecanismos possíveis de forma a aumentarem o nível de extração de mais-valia.

Embora proclame-se, em alto e bom som, que com a contrarreforma do ensino médio vivenciaremos um novo momento da educação pública brasileira, acreditamos que esta contrarreforma reafirma as práticas duais de formação humana advogadas pelas elites brasileiras (Motta e Frigotto, 2017; Ferretti e Silva, 2017). 
Ao concluir a discussão sobre a relação entre a reforma do ensino médio e a inserção precarizada dos jovens no mercado de trabalho, não podemos deixar de considerar que um dos aspectos dessa reforma refere-se ao empobrecimento da formação dos jovens oriundos da classe trabalhadora.

No nosso entender, uma questão que deve ser levada em consideração é que o princípio norteador desta reforma é a continuidade da histórica dualidade vivenciada na educação brasileira, pois, como nos ajudou Paolo Nosella (2011) a pensar, o objetivo de qualquer reforma educacional deve ser buscado, não tanto pelo dito, mas em seus fins ocultos:

A expressão 'princípio' aponta para a causa final do processo educativo. Com efeito, a causa final está intencionalmente presente no ser desde a sua primeira concepção informando todo seu processo, dando-lhe unitariedade e funcionalidade, conforme a célebre expressão da filosofia antiga: o último na execução é também o primeiro na intenção. Ou seja: o objetivo final é o princípio organizativo e executivo de todo o processo. Em outras palavras, o 'princípio educativo' é a razão última que informa todo o processo escolar, é a perspectiva real e de longo alcance assumida pelos educandos e pelos educadores. Nesta perspectiva selecionam-se e tomam sentido os conteúdos (Nosella, 2011, p. 10).

Esta reforma não objetiva assegurar um novo princípio educativo. Expressa, sim, o princípio que visa aprofundar as relações de subordinação das camadas populares ao processo de acumulação do capital. De uma forma dissimulada e contando com o apoio da grande imprensa, objetiva assegurar uma nova hegemonia das classes ligadas ao capital internacional. Assim, a reforma do ensino médio, a reforma trabalhista, a reforma da previdência em articulação com a aprovação da emenda constitucional que estabelece o controle dos gastos públicos expressam a ofensiva das elites, que tomaram o poder de assalto, e visam assegurar um modelo de desenvolvimento voltado para o processo de reprodução do capital em escala ampliada.

Resumen En este artículo se discute la relación entre la inserción de los jóvenes en el mercado de trabajo y su pasaje por la enseñanza secundaria. Se tiene como argumento central que la reciente contrarreforma de la enseñanza secundaria no garantizará oportunidades universales para la conclusión de la educación básica, pero sí fomentará la formación precarizada en las escuelas públicas y reforzará la precarización del trabajo juvenil. Se analizaron metodológicamente datos referentes al pasaje de la juventud por el proceso de escolarización y su forma de inserción en el mercado de trabajo. Como fuentes primarias básica se analizaron datos proporcionados por el Instituto Brasileño de Geografía y Estadística, en sus Investigaciones Nacionales de Muestra Domiciliaria y Censos; investigaciones realizadas por el Ministerio de Trabajo, específicamente los datos del Registro General de Empleados y Desempleados y de la Relación Anual de Informaciones Sociales; y los datos proporcionados por el Instituto Nacional de Estudios e Investigaciones Educativas Anísio Teixeira.

Palabras clave juventud; trabajo; enseñanza secundaria. 


\section{Notas}

${ }^{1}$ Universidade Federal de Pernambuco, Programa de Pós-Graduação em Educação, Recife, Pernambuco, Brasil.

<ramono@elogica.com.br>

Correspondência: Rua Sucupira do Norte, 286/201, Piedade, CEP 54410-362, Jaboatão dos Guararapes, Pernambuco, Brasil.

${ }^{2}$ Iniciado em 1995 pelo Ministério do Trabalho, teve como meta qualificar cerca de 15 milhões de trabalhadores anualmente. Em 2003, no governo Lula, foi substituído pelo PNQ.

${ }^{3}$ Criado em 2011, expandiu a oferta de educação profissional técnica de nível médio e de cursos de formação inicial. Ampliou a oferta da educação profissional na rede federal de educação tecnológica e estabeleceu convênios do governo federal com a iniciativa privada (Pereira, 2016).

4 “O Cadastro Geral de Empregados e Desempregados - Caged foi criado pelo Governo Federal, através da lei n. 4.923/65, que instituiu o registro permanente de admissões e dispensa de empregados, sob o regime da Consolidação das Leis do Trabalho - CLT". (Ver em <http://trabalho.gov.br/trabalhador-caged $>$ ).

${ }^{5}$ Relatório anual do Ministério do Trabalho e Emprego estruturado com base nas informações relativas ao mercado de trabalho formal.

${ }^{6}$ A taxa de escolarização bruta é a relação entre a população de determinada faixa etária matriculada em qualquer nível de ensino e o total de pessoas nesta mesma faixa etária.

${ }^{7}$ Encontramos sutis variações entre os documentos governamentais e os de instituições de pesquisa em relação a este índice.

${ }^{8} \mathrm{~A}$ taxa de frequência líquida é a relação entre a população de determinada faixa etária matriculada no nível de escolarização ideal para esta idade e o total de pessoas nesta mesma faixa etária.

\section{Referências}

BRASIL. Exposição de motivos (EM) n. 00084/2016/MEC. Medida provisória n. 746, de 22 de setembro de 2016. Disponível em: $<$ http://www.planalto.gov.br/ccivil_03/_ ato2015-2018/2016/Exm/Exm-MP-746-16. pdf>. Acesso: 23 nov. 2017.

CASTRO, Jorge A.; Aquino, Luseni. Juventude e politicas sociais no Brasil. Brasília: IPEA, 2008. 153 p. (Texto para discussão, n. 1.335).

CEPAL/UNESCO. Educación y conocimiento: eje de la transformación productiva con equidad. Santiago de Chile, agosto de 1992.
DAYRELL, Juarez. A escola "faz" as juventudes? Reflexão em torno da socialização juvenil. Educação \& Sociedade, Campinas, v. 28, n. 100, esp, p. 1.105-1.128, 2007.

DAYRELL, Juarez; Jesus, Rodrigo E. A exclusão de jovens de 15 a 17 anos no ensino médio no Brasil: desafios e perspectivas. Relatório de pesquisa. Belo Horizonte: Observatório da Juventude, UFMG, 2013

DIEESE. Anuário do Sistema Público de Emprego, Trabalho e Renda 2015: juventude. São Paulo, 2015. Disponível em: < https://www.dieese. org.br/anuario/2015/sistPubLivreto6Jovens. pdf $>$. Acesso em: 23 nov. 2017. 
FERRETTI, Celso J.; SILVA, Mônica R. Reforma do ensino médio no contexto da medida provisória n. 746/2016: Estado, currículo e disputas por hegemonia. Educação \& Sociedade, Campinas, v. 38, n. 139 , p. 385-404, abr.-jun. 2017.

FRIGOTTO, Gaudêncio. A produtividade da escola improdutiva: um (re) exame das relações entre educação e estrutura econômica social e capitalista. São Paulo: Cortez, 1989.

GENTILI, Pablo. Educar para o desemprego: a desintegração da promessa integradora In FRIGOTTO, Gaudêncio (org.). Educação e crise do trabalho: perspectivas de final de século. Petrópolis: Vozes, 1999. p. 76-99.

IBGE. Censo demográfico 2010: características da população e dos domicílios - resultados do universo. Rio de Janeiro, 2011. Disponível em: <https://biblioteca.ibge.gov.br/visualizacao/periodicos/93/cd_2010_caracteristicas_populacao_domicilios.pdf $>$. Acesso em: 23 nov. 2017.

IBGE. Pesquisa Nacional por Amostra de Domicílios - 2013. Rio de Janeiro, 2014. Disponível em: http://biblioteca.ibge.gov.br/visualizacao/ periodicos/59/pnad_2013_v33_br.pdf. Acesso em: 10 jul. 2014.

IBGE. Sintese de Indicadores Sociais - 2015: uma análise das condições de vida da população brasileira. Rio de Janeiro, 2015. Disponível em: $<$ http://biblioteca.ibge.gov.br/visualizacao/ livros/liv95011.pdf>. Acesso em: 10 set. 2016.

IBGE. Censo demográfico 2010: Educação e Deslocamento - resultados da amostra. Rio de Janeiro, 2012. Disponível em: < http:// biblioteca.ibge.gov.br/visualizacao/periodicos/545/cd_2010_educacao_e_deslocamento. pdf $>$. Acesso em: 10 set. 2016.

IBGE. Sintese de Indicadores Sociais 2016: uma análise das condições de vida da população brasileira. Rio de Janeiro, 2016. Disponível em: <http://biblioteca.ibge.gov.br/visualizacao/livros/liv98965.pdf $>$. Acesso em: 15 set. 2017
INEP. Sinopse estatística da educação básica 2015. Brasília, 2016. Disponível em: <http:// portal.inep.gov.br/web/guest/sinopses-estatisticas-da-educacao-basic >. Acesso em: 7 dez. 2017.

KUENZER, Acácia Z. Da dualidade assumida à dualidade negada: o discurso da flexibilização justifica a inclusão excludente. Educação e Sociedade, Campinas, v. 28, n. 100, esp., p. 1.153-1.178, out. 2007.

KUENZER, Acácia Z. Trabalho e escola: a flexibilização do ensino médio no contexto do regime de acumulação flexível. Educação \& Sociedade, Campinas, v. 38, n. 139, p. 331-354, abr.-jun. 2017.

MOTTA, Vânia C.; FRIGOTTO, Gaudêncio. Por que a urgência da reforma do ensino médio? Medida provisória n. 754/2016 (Lei n. 13.415/2017). Educação \& Sociedade, Campinas, v. 38, n. 139, p. 355-372, abr.-jun. 2017.

NOSELLA, Paolo. Ensino médio: em busca do princípio pedagógico. Educação \&Sociedade, Campinas, v. 32, n. 117, p. 1.051-1.066, out.-dez. 2011.

OLIVEIRA, Ramon. Precarização do trabalho: a funcionalidade da educação profissional. Revista Diálogo Educacional, Curitiba, v. 15, n. 44 , p. 247-266, jan.-abr. 2015.

OLIVEIRA, Ramon. Empregabilidade. In: PEREIRA, Isabel B.; LIMA, Júlio C. F. Dicionário da Educação Profissional em Saúde. Rio de Janeiro: EPSJV, 2006, p. 141-146.

OLIVEIRA, Ramon. Empresariado industrial e educação brasileira: qualificar para competir. São Paulo: Cortez, 2005.

PEREIRA, André L. G. A implementação dos cursos técnicos do Pronatec no campus Vitória de Santo Antão do IFPE. 2016. 228 f. Dissertação (Mestrado em Educação) - Universidade Federal de Pernambuco, Centro de Educação, Recife, 2016.

POCHMANN, Márcio. A batalha do primeiro emprego: as perspectivas e a situação atual do jovem no mercado de trabalho brasileiro. São Paulo: Publisher Brasil, 2000 
POCHMANN, Márcio. O emprego na globalização: a nova divisão internacional do trabalho e os caminhos que o Brasil escolheu. São Paulo: Boitempo, 2001.

POCHMANN, Márcio. O emprego no desenvolvimento da nação. São Paulo: Boitempo, 2008.

RAMOS, Marise N. A pedagogia das competências: autonomia ou adaptação. São Paulo: Cortez, 2001.

SPOSITO, Marília. A sociabilidade juvenil e a rua: novos conflitos e ação coletiva na cidade. Tempo Social: Revista de Sociologia da USP, São Paulo, v. 5 n. 1-2, p. 161-178, 1993.

SPOSITO, Marília; CARRANO, Paulo. Juventude e políticas públicas no Brasil. Revista Brasileira de Educação, Rio de Janeiro, n. 24, p. 16-39, set.-dez. 2003.

TODOS PELA EDUCAÇÃO. Anuário Brasileiro da Educação Básica 2017. 2017 Disponível em: <https://www.todospelaeducacao.org. br//arquivos/biblioteca/anuario_brasileiro_ da_educacao_basica_2017_com_marcadores. pdf $>$. Acesso em: 15 set. 2017.
TORRES, Haroldo G. et al. O que pensam os jovens de baixa renda sobre a escola. Relatório final. São Paulo: Fundação Victor Civita, 2013. Disponível em: <www.fvc.org.br/estudos>. Acesso em: 10 fev. 2016.

WAISELFISZ, Julio J. Mapa da violência no Brasil 2014: os jovens do Brasil. Brasília: Secretaria-Geral da Presidência da República/Secretaria Nacional de Juventude/Secretaria de Políticas de Promoção da Igualdade Racial, 2014. 189p. Disponível em: <http://www.mapadaviolencia.org.br/pdf2014/Mapa2014_JovensBrasil. pdf $>$. Acesso em: 23 nov. 2017.

Recebido em 05/07/2017

Aprovado em 06/11/2017 
